\title{
A Practical Guide to Healthy Living ${ }^{1}$
}

\section{Wendy W. Lynch, Annie Wallau, Melanie Thomas, Wendy Mussoline, and Catherine Campbell ${ }^{2}$}

When you hear the term "wellness," you may initially think of your physical health. However, wellness is defined by more than the physical body. True wellness is the result of harmony and balance among multiple dimensions of wellness in our lives. These dimensions of wellness include spiritual, emotional, cognitive (thoughts), physical, financial, social, and environmental ones. Committing to maintain a balance among these dimensions supports a good quality of life (Stoewen, 2017). For example, our thoughts, feelings, and beliefs reside within our emotional and spiritual dimensions, but they directly affect our physical well-being.

The connections between dimensions are complex, and disruptions to this harmony, such as stress, may have physical consequences. Stress can lead to a temporary rise in blood pressure, or affect lifestyle choices such as diet and exercise. In addition, chronic stress can increase your risk of heartrelated health problems. Stress is an internal response, yet it is triggered by external factors such as financial problems, personal safety, or environmental concerns. Physical symptoms of stress can include a rapid heartbeat, sweating, headaches, and muscle tension. Stress can also affect our thinking and feeling through difficulty remembering, poor decision-making, lack of attention, or irritability. These examples demonstrate how the dimensions of wellness are interconnected. However, they also show how making changes to one dimension may simultaneously influence others.

This publication provides a guide to implementing healthy living and wellness practices. It is designed for individuals who are interested in healthy lifestyles. Consider incorporating some of the following lifestyle practices to find balance across each of the dimensions and take control of your individual wellness.

\section{Spiritual Wellness}

Spiritual wellness involves finding purpose, value, and meaning in your life. Spiritual wellness can be achieved through faith, values, ethics, and morals (Hrabe, Mazurek Melnyk, \& Neale, 2019). Regardless of whether you belong to an organized religious entity, participating in activities that are consistent with your beliefs and values will help you to explore your inner self and develop harmony with the outside world.

\section{Take the time for personal reflection daily.}

- Try journaling. Set aside a certain time of the day to write down your thoughts.

- Spend quiet time alone.

1. This document is FCS3359, one of a series of the Department of Family, Youth and Community Sciences, UF/IFAS Extension. Original publication date September 2021. Visit the EDIS website at https://edis.ifas.ufl.edu for the currently supported version of this publication.

2. Wendy W. Lynch, regional specialized agent, UF/IFAS Extension Central District, and Extension agent, family and consumer sciences/food systems, UF/ IFAS Extension St. Johns County; Annie Wallau, county Extension director and Extension agent II, MNM, UF/IFAS Extension Clay County—Northeast; Melanie Thomas, county Extension director, Extension agent, family and consumer sciences, UF/IFAS Extension Flagler County; Wendy Mussoline, $\mathrm{PhD}$, multi-county Extension agent, agriculture, UF/IFAS Extension Flagler and Putnam Counties; and Catherine Campbell, PhD, assistant professor, community food systems, Department of Family, Youth and Community Sciences, UF/IFAS Mid-Florida Research and Education Center; UF/IFAS Extension, Gainesville, FL 32611.

The Institute of Food and Agricultural Sciences (IFAS) is an Equal Opportunity Institution authorized to provide research, educational information and other services

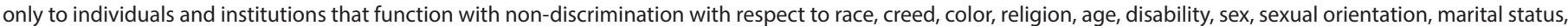

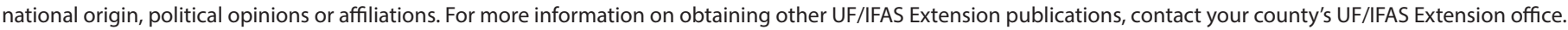
U.S. Department of Agriculture, UF/IFAS Extension Service, University of Florida, IFAS, Florida A \& M University Cooperative Extension Program, and Boards of County Commissioners Cooperating. Nick T. Place, dean for UF/IFAS Extension. 


\section{Develop a mind-body connection.}

- Practice yoga in your community at a local yoga studio or independently using a yoga app or online videos.

- Take time to meditate daily. Not sure where to start? Check out the mindfulness and meditation resources at www.wellness.med.ufl.edu.

\section{Seek meaning and purpose in your life.}

- Study religion and philosophy, and/or take time for prayer.

- Serve the community through volunteer work. Search for a local rescue mission or food pantry or explore initiatives that align with your personal passion.

\section{Emotional Wellness}

The National Institutes of Health define emotional wellness as the "ability to successfully handle life's stressors and adapt to change and difficult times" (National Institutes of Health, 2018a). The ability to understand, manage, and respect your feelings, values, and attitudes along with respecting the feelings of others can help contribute to your emotional wellness. Find ways of managing your emotions in a constructive way. Choose one of the following strategies for improving your emotional health.

\section{Reduce stress.}

- Get plenty of restful sleep. Adults should aim for seven to nine hours per night (Centers for Disease Control and Prevention, 2017).

- Exercise each day. Including 30 minutes of walking per day can help boost your mood and improve your health.

- Talk to your healthcare provider about possible treatments if stress is affecting your relationships or ability to work.

\section{Be mindful.}

- Practice deep breathing when your emotions are running high. Breathe in through your nose to a count of four, hold for one second, and then exhale through the mouth to a count of five. Repeat often.

- Incorporate mindful eating. Be aware of taste, textures, and flavors in each bite, and listen to your body when you are hungry and full.

- Find mindfulness resources in your community, including yoga and meditation classes, mindfulness-based stress reduction programs, and books.

\section{Generate a positive outlook.}

- Practice forgiveness towards yourself and other people.
- Identify at least one positive moment each day. If you journal, include this positive moment as part of your daily entry. Better yet, share it with a friend.

\section{Intellectual Wellness}

Intellectual wellness includes finding creative ways to improve your knowledge and skills. It includes challenging yourself, using critical thinking and problem-solving skills, and keeping your mind active. Intellectual wellness "reflects a commitment to lifelong learning" (Strout \& Howard, 2012). There are several activities to engage in to support intellectual wellness. Incorporating more lifestyle practices from each of the dimensions of wellness increases cognitive benefits (Strout \& Howard, 2012).

\section{Seek out educational opportunities (National Institute on Aging, 2020).}

- Play an instrument. Choose a new instrument to learn how to play.

- Learn a new language. Take a formal class or use an app to help you develop proficiency in another language.

- Connect with the arts. Visit a museum, exhibit, or theater.

\section{Explore personal interests.}

- Engage in a debate or thought-provoking conversation. Have a conversation with a friend, colleague, or family member.

- Read a book, magazine, or tablet. Find articles to stay up to date on current events.

- Plan a trip. Research a place you would like to visit.

\section{Play games (Howard et al., 2016).}

- Complete a crossword puzzle, word scramble, or number game.

- Play a digital game. Choose an action-based or strategy game using an app, computer software, or online platform (Vailati Riboni et al., 2020).

\section{Physical Wellness}

Physical wellness includes keeping your body healthy through adequate nutrition and daily activity. Proper nutrition is consuming the right-sized portions of nutrientdense food and beverages to meet your individual needs. Aim for 150 minutes or more of activity and include strength training and flexibility exercises in your weekly routine. Additional self-care practices such as getting adequate sleep and maintaining proper oral health are also essential for promoting physical wellness. Self-care looks different for everyone. It includes the things you need to 
do, and informed decisions you need to make to be your healthiest self.

\section{Engage in physical activity.}

- Walk or bike to school or work.

- Take your dog for a 15-minute walk around the neighborhood.

- Walk, bike, or play a sport at local county parks, trails, or recreation centers.

- Join a local fitness center, health club, or community fitness center.

- Participate in an online exercise class.

- Add variety to your daily movement. Try a new route, new equipment, or a different routine.

\section{Eat healthy foods.}

- Shop for local and seasonal produce with the "Fresh from Florida" logo. Find out what is in season at https://www. followfreshfromflorida.com/.

- Check out community-supported agriculture (CSAs) and farmers' markets in your area. Go online to https:// www.fdacs.gov and search for "community supported agriculture" and "community farmers' markets."

- Include a variety of colors from each food group in your meal planning.

- Choose nutrient-dense foods most often. These foods provide vitamins, minerals, and other healthy nutrients.

- Read Nutrition Facts Labels to guide your selections in the market and restaurants. This is an excellent way to help you select healthier options. For more information on reading a Nutrition Facts Label, visit https://www.fda. gov. Search for "Understand Nutrition Facts Label."

\section{Practice self-care.}

- Maintain a healthy diet and exercise consistently.

- Practice good personal hygiene.

- Choose healthy living habits, such as being smoke-free.

- Set a sleep schedule for both morning and evening. Be consistent with your wake and sleep times, even on the weekends.

- Schedule visits with your healthcare provider, eye doctor, and dentist for preventative care and routine checkups. Write a list of questions to ask during your visits. You are the best advocate for your health.

\section{Financial Wellness}

Financial instability is one of the most common stressors for individuals. Reducing or minimizing financial stress helps to increase overall wellness (Weida, Phojanakong, Patel, \& Chilton, 2020). However, financial values, needs, and circumstances are unique and vary from person to person. A potentially stressful financial burden for one person may not be an issue for another. Even for a single person, financial needs and responsibilities may change throughout one's lifetime.

Financial wellness, on the other hand, is a feeling of satisfaction related to both current and future finances. Managing your resources to live within your means, making informed financial decisions and investments, setting realistic goals, and preparing for short-term and long-term needs or emergencies are fundamental tips for financial stability.

\section{Find ways to manage finances.}

- Develop a household budget and track your spending. For a step-by-step guide for creating a budget, visit https://edis.ifas.ufl.edu/he827.

- Open a savings account and deposit monthly.

- Keep organized records of finances.

- Avoid credit card debt. For more information on credit, visit https://edis.ifas.ufl.edu/ topic_series_you_and_your_credit.

- Plan and prepare meals at home.

- Use your food dollars wisely. Look for ways to savecheck the weekly store circular, use coupons and store rewards, and stick to your grocery list.

\section{Make informed financial decisions.}

- Plan ahead. Identify potential financial problems before they start.

- Learn about the different types of bank accounts and their associated fees.

- Review your annual credit reports. Visit https://www. annualcreditreport.com. You will be asked to provide your Social Security number to receive your free report.

- Meet with a financial and/or retirement planner.

- Make arrangements for the end of life.

\section{Social Wellness}

Developing and maintaining positive social relationships are important throughout your lifetime. Having healthy and close relationships and experiencing social connectedness, 
whether with friends, family, or your community, have been shown to impact your short- and long-term health (Umberson \& Montez, 2010). Social relationships are essential for overall health and survival (Holt-Lunstad, Robles, \& Sbarra, 2017).

\section{Attend a social engagement.}

- Look for local events such as a concert in the park, an art walk, or a festival.

- Support your annual county fair as an attendee, exhibitor, or volunteer.

- Participate in U-Pick opportunities in your community. You can find Florida U-Pick Farms by visiting https:// www.fdacs.gov/Consumer-Resources/Buy-Fresh-FromFlorida/U-Pick-Farms and entering your city, county, or zip code.

\section{Participate in a social group within your community.}

- Identify an established service group that meets regularly, such as a local charity or annual events planning group. Gather for group fitness, or play sports or recreational games. This can be online, at a community center, or with a fitness club.

- Volunteer with organizations like UF/IFAS Extension that host project-specific community service events. Check your local newspaper's community calendar, social media, or a cell phone application that connects you to neighborhood and community events.

- Find an in-person or online group with similar interests and goals to promote social wellness. Support groups offer emotional and practical support and encouragement, and provide a safe space to share experiences.

\section{Spend quality time with your pets.}

- Take your pet for a walk around the neighborhood, in a park, or on the beach. Pets provide companionship and engagement, a need for routine, a sense of purpose and comfort, and social support (National Institutes of Health, 2018b).

- Schedule daily playtime with your furry friend.

\section{Spend time with family and/or friends.}

- Schedule a standing phone or video chat date.

- Host a game night. You can play traditional board and card games or take it outdoors for a fun backyard game.

- Plan a day trip.

- Enjoy a meal and movie.

\section{Environmental Wellness}

Your indoor and outdoor environment can have an important impact on your health and well-being. Spending time with nature by viewing green space, growing plants, or visiting parks can have therapeutic mental health and stress relief benefits (Barton \& Rogerson, 2017). The environmental quality of your surroundings can affect your health. There are steps you can take to help maintain or improve the quality of your environment.

\section{Learn about and engage with nature.}

- Go on a walk or spend time in nature to reduce stress and boost your mood.

- Visit a Florida State Park (https://www.floridastateparks. $\operatorname{org} /$ ).

- Plant a garden to grow your own food. Even if you do not have a yard, you can grow herbs and other small plants on a porch or windowsill.

- Become a Florida Master Gardener. Learn about gardening, teaching others about gardening, and giving back to your community (https://gardeningsolutions.ifas.ufl.edu/ mastergardener/).

- Become a Florida Master Naturalist. Learn more about Florida's unique ecosystems and wildlife (https://masternaturalist.ifas.ufl.edu/).

\section{Protect and improve your indoor and outdoor environments.}

- Reduce your use of pesticides by using integrated pest management techniques. Visit https://gardeningsolutions. ifas.ufl.edu/ and search "integrated pest management."

- Turn off unnecessary outside lights at night. Artificial light at night can affect the natural behavior of certain animals and insects, such as songbirds and honeybees.

- Help to preserve and improve natural areas by removing trash and litter.

- Protect your water quality by only letting rainwater go down a storm drain. Do not pour oil, paint, or unused chemicals down a storm drain.

- To protect your indoor air quality, ensure good ventilation and avoid smoking indoors. Prevent mold by monitoring for leaks under sinks and in showers.

\section{Conserve resources.}

- Find out what type of recycling program is available in your community and sort your waste accordingly. 
- Minimize the need for landscape irrigation and chemical fertilizers by selecting appropriate plants and reducing the amount of turfgrass at your home. The FloridaFriendly Landscaping ${ }^{\mathrm{TM}}$ Program has tips on how to fertilize (https://ffl.ifas.ufl.edu/).

- Reduce your food waste by composting. Find a quick composting tutorial at https://sfyl.ifas.ufl.edu/ sarasota/natural-resources/waste-reduction/composting/ quick-tutorial/.

- Conserve energy in your home by turning off lights, purchasing energy-efficient light bulbs, and keeping your thermostat at $68^{\circ} \mathrm{F}$ in the winter and $78^{\circ} \mathrm{F}$ in the summer.

- Reduce your carbon footprint by walking and biking for transportation whenever it is safe and possible for you to do so.

\section{Summary}

Recognizing your capabilities within the core dimensions of your life and taking practical steps toward improvement are key to balanced living. This publication is meant to be a practical guide that you can revisit from time to time to monitor your growth in a particular area. By integrating some of these strategic habits into the spiritual, emotional, physical, financial, social, and environmental dimensions of your life, you can manage common stressors and enjoy a healthier life.

\section{References}

Barton, J., \& Rogerson, M. (2017). The Importance of Greenspace for Mental Health. BJPsych International, 14(4), 79-81. https://doi.org/10.1192/s2056474000002051

Centers for Disease Control and Prevention (2017). How Much Sleep Do I Need? https://www.cdc.gov/sleep/ about_sleep/how_much_sleep.html

Holt-Lunstad, J., Robles, T. F., \& Sbarra, D. A. (2017). Advancing Social Connection as a Public Health Priority in the United States. American Psychologist, 72(6), 517-530. https://doi.org/10.1037/amp0000103

Howard, E. P., Morris, J. N., Steel, K., Strout, K. A., Fries, B. E., Moore, A., \& Garms-Homolová, V. (2016). Short-Term Lifestyle Strategies for Sustaining Cognitive Status. BioMed Research International, 2016. https://doi. org/10.1155/2016/7405748

Hrabe, D., Mazurek Melnyk, B., \& Neale, S. (2019). Spiritual Wellness: A Journey Toward Wholeness. https://www.myamericannurse.com/spiritual-wellness-journey-wholeness/
National Institute on Aging. (2020). Cognitive Health and Older Adults. https://www.nia.nih.gov/health/ cognitive-health-and-older-adults

National Institutes of Health. (2018a). Emotional Wellness Toolkit. https://www.nih.gov/health-information/ emotional-wellness-toolkit

National Institutes of Health. (2018b). The Power of Pets. https://newsinhealth.nih.gov/2018/02/power-pets

Stoewen, D. L. (2017). Dimensions of Wellness: Change Your Habits, Change Your Life. La Revue Veterinaire Canadienne, 58(8), 861-862.

Strout, K., \& Howard, E. (2012). The Six Dimensions of Wellness and Cognition in Aging Adults. Journal of Holistic Nursing: Official Journal of the American Holistic Nurses' Association, 30, 195-204. doi:10.1177/0898010112440883.

Umberson, D., \& Montez, J. K. (2010). Social Relationships and Health: A Flashpoint for Health Policy. Journal of Health and Social Behavior, 51(Suppl), S54-S66. https://doi. org/10.1177/0022146510383501

Vailati Riboni, F., Comazzi, B., Bercovitz, K., Castelnuovo, G., Molinari, E., \& Pagnini, F. (2020). TechnologicallyEnhanced Psychological Interventions for Older Adults: A Scoping Review. BMC Geriatrics, 20(1), 191. https://doi. org/10.1186/s12877-020-01594-9

Weida, E. B., Phojanakong, P., Patel, F., \& Chilton, M. (2020). Financial Health as a Measurable Social Determinant of Health. PLoS ONE 15(5), e0233359. https://doi. org/10.1371/journal.pone.0233359 